\section{Cerium oxide nanoclusters: commensurate with concepts of polyoxometalate chemistry? $\dagger$}

\author{
Iurii L. Malaestean, ${ }^{a}$ Arkady Ellern, ${ }^{b}$ Svetlana Baca ${ }^{a}$ and Paul Kögerler ${ }^{*} a$ \\ Received 31st July 2011, Accepted 20th September 2011 \\ DOI: $10.1039 / \mathrm{c} 1 \mathrm{cc} 14725 \mathrm{k}$
}

The mixed-valent cerium(III/IV) oxide clusters $\left\{\mathrm{Ce}_{10}\right\}$ and $\left\{\mathrm{Ce}_{22}\right\}$, derived from condensation reactions of cerium carboxylate coordination polymers, exhibit molecular growth tendencies similar to those of 'classical' group $\mathrm{V}$ and VI polyoxometalates, but with increasing nuclearity approach the structure of the parental oxide, $\mathrm{CeO}_{2}$.

Molecular metal oxide clusters provide versatile and robust scaffolds for a range of materials as they allow secondary functionalization with groups with e.g. specific electronic, magnetic, or catalytic functionalities. ${ }^{1}$ For example, magnetically functionalized polyoxomolybdates and -tungstates have been employed to realize magnetic molecules comprising large spin polytopes which adopt symmetry features of the (diamagnetic) molybdate or tungstate frameworks, resulting in unusual magnetic phenomena. ${ }^{2}$ In a search for alternative metal oxide architectures amenable to subsequent functionalization with spin centers, we explored zirconium(IV) oxide-based structures where various magnetic derivatives of highly condensed $\left\{\mathrm{Zr}_{6} \mathrm{O}_{4}(\mathrm{OH})_{4}\right\}$ and $\left\{\mathrm{Zr}_{12} \mathrm{O}_{11}(\mathrm{OH})_{11}\right\}$-based structures allow for a direct coordination of $3 \mathrm{~d}$ ions to the metal oxide core. ${ }^{3}$ Motivated by the fact that a sole polynuclear $\left\{\mathrm{Ce}^{\mathrm{IV}}{ }_{6} \mathrm{O}_{8}\right\}$ structure is known ${ }^{4}$ and that several high-nuclearity lanthanide coordination complexes feature $\operatorname{Ln}_{n} \mathrm{O}_{m}$ cores, though predominantly for later lanthanides, ${ }^{5}$ we are focusing on cerium oxide structures where the high coordination numbers (up to 12) of Ce(III) and $\mathrm{Ce}(\mathrm{Iv})$ enable flexible coordination modes, potentially resulting in more diverse metal oxide cluster architectures. Moreover, the redox activity of cerium(III/IV) renders $\left\{\mathrm{Ce}_{n} \mathrm{O}_{m}\right\}$ clusters similar to polyoxovanadates or -molybdates where the charge, in particular the electron density at the oxygen sites defining the cluster's surface, controls the nucleophilicity and thus the extent of molecular growth based on condensation reactions. ${ }^{6}$

We herein present two high-nuclearity, spherical cerium(III/IV) oxide clusters, $\left[\mathrm{NaCe}_{10} \mathrm{O}_{7}(\mathrm{OH})(\mathrm{ib})_{14}\left(\mathrm{HCO}_{2}\right)(\mathrm{mda})_{5}\right]$ (1) and $\left[\mathrm{Ce}_{22} \mathrm{O}_{20}(\mathrm{OH})_{4}(\mathrm{ib})_{26}(\mathrm{tme})_{4}\right]$ (2), formed in the presence of chelating ligands (Hib: isobutyric acid, $\mathrm{H}_{3}$ tme: 1,1,1-tris(hydroxymethyl)ethane, $\mathrm{H}_{2}$ mda: $\mathrm{N}$-methyldiethanolamine),

\footnotetext{
${ }^{a}$ Institute of Inorganic Chemistry, RWTH Aachen University, 52070 Aachen, Germany.E-mail: paul.koegerler@ac.rwth-aachen.de; Fax: + 49-241-80-92642; Tel: + 49-241-80-93642

${ }^{b}$ Ames Laboratory, Iowa State University, Ames, IA 50011, USA

$\dagger$ Electronic supplementary information (ESI) available: Crystallographic details and BVS calculations, structural description of $\mathbf{3}$. CCDC 809326, 836104 and 836105. For ESI and crystallographic data in CIF or other electronic format see DOI: $10.1039 / \mathrm{clcc} 14725 \mathrm{k}$
}

which exemplify the extent to which structural and reactivity concepts of polyoxometalate chemistry are applicable. Synthesis of the charge-neutral $\left\{\mathrm{Ce}_{10}\right\}$ and $\left\{\mathrm{Ce}_{22}\right\}$ clusters starts from simple cerium(III) carboxylate precursors, e.g. the helical 1D coordination polymer $\left[\mathrm{Ce}_{2}^{\mathrm{III}}(\mathrm{ib})_{6}\left(\mathrm{H}_{2} \mathrm{O}\right)_{3}\right]_{n}(3)$, under controlled condensation conditions, i.e. in organic solvents $(n-\mathrm{PrOH}$ or $\mathrm{MeCN}$ ) in the presence of defined minimal amounts of water, introduced via the precursors. $\ddagger$ Next to the structure-directing effects of the organic chelating ligands, exposure of the heated reaction solutions to air oxygen is a key reaction parameter in the formation of $\mathbf{1}$ and $\mathbf{2}$, as it controls the $\mathrm{Ce}$ (III) : $\mathrm{Ce}$ (IV) ratio.

Single-crystal X-ray diffraction analysis of $\mathbf{1}$ (space group $P 2_{1} / c$ ) reveals the $C_{\mathrm{i}}$-symmetric cluster $\left[\mathrm{NaCe}_{10} \mathrm{O}_{7}(\mathrm{OH})(\mathrm{ib})_{14^{-}}\right.$ $\left.\left(\mathrm{HCO}_{2}\right)(\mathrm{mda})_{5}\right]$ to consist of a decanuclear $\left\{\mathrm{Ce}_{10} \mathrm{O}_{7}(\mathrm{OH})\right\}^{24+}$ core decorated with one $\mathrm{Na}^{+}$ion and terminated by 15 bridging carboxylates and five doubly deprotonated $\mathrm{mda}^{2-}$ groups $\left(1.8 \times 1.7 \times 1.6 \mathrm{~nm}^{3}\right.$; Fig. 1$)$. Note that the presence of $\mathrm{Na}^{+}$in the reaction solution is required for the formation of this $\left\{\mathrm{Ce}_{10}\right\}$ compound. One of the carboxylate groups was identified as formate, presumably a decomposition product. The $\left\{\mathrm{Ce}_{10} \mathrm{O}_{7}(\mathrm{OH})\right\}$ core can be described as a domed, body-centered pentagonal $\left\{\mathrm{Ce}_{5}(\mathrm{Ce})(\mu-\mathrm{O})_{6}\right\}$ building block reminiscent of the analogous $\left\{\mathrm{Mo}_{5}(\mathrm{Mo})\right\}$ building blocks abundant in larger polyoxomolybdates, e.g. of the Keplerate or the molybdenum blue wheel type. ${ }^{7}$ One $\left\{\mathrm{Ce}_{2}(\mu-\mathrm{O})_{2}\right\}$ and one $\left\{\mathrm{Ce}_{2}(\mu-\mathrm{O})\right\}$ group are attached side-on to the $\left\{\mathrm{Ce}_{5}(\mathrm{Ce})\right\}$ pentagon (Fig. 2a). Alternatively, the $\left\{\mathrm{Ce}_{10}\right\}$ skeleton can formally be decomposed into a nine-fold coordinated Ce site around which four $\mathrm{Ce}_{3}$ triads are arranged: a discrete $\mathrm{Ce}_{3}$ triangle next to the $\mathrm{Na}^{+}$site and a $\mathrm{Ce}_{8}$ ring of three corner-sharing $\mathrm{Ce}_{3}$ triangles (Fig. 1b) - a structural variation of the Keggin structure type, also featuring four (discrete) $\mathrm{M}_{3}$ triangles usually templated by a central (tetrahedral) heterogroup. ${ }^{6}$ Bond valence sum (BVS) calculations indicate a formal oxidation state of + III for the central Ce site (BVS: 2.97), while the nine remaining Ce sites are + IV (BVS: 4.45-4.90), see Table S2 (ESI $\dagger) .{ }^{8}$ The Ce sites in 1 adopt coordination numbers of eight $\left(\mathrm{O}_{8}, \mathrm{O}_{7} \mathrm{~N}\right)$, nine $\left(\mathrm{O}_{9}\right.$, $\left.\mathrm{O}_{8} \mathrm{~N}\right)$, and ten $\left(\mathrm{O}_{9} \mathrm{~N}\right)$. Ce- $\mathrm{O}$ distances of 2.204-2.706 $\AA$ and Ce-N of 2.665-2.678 $\AA$ for Ce(IV), 2.461-2.677 $\AA$ for Ce(III) fall within the usual range for related $\mathrm{Ce}$ (III) and Ce(IV) coordination compounds. $^{8}$ BVS calculations for all oxygen atoms identify O9 as a $\mu_{3}-\mathrm{OH}$ group (BVS: 1.32).

2 crystallizes in space group $C 2 / c$; the $\left\{\mathrm{Ce}_{22}\right\}$ cluster $(1.9 \times$ $1.9 \times 1.7 \mathrm{~nm}^{3}$; Fig. $2 \mathrm{~b}$ and 3 ) is based on a highly condensed 


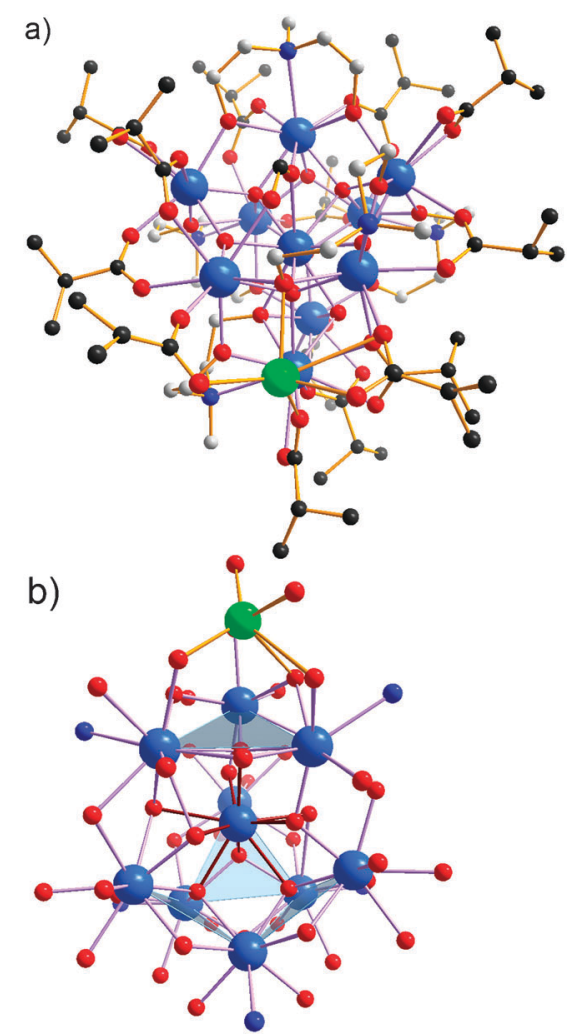

Fig. 1 (a) Structure of the $\left\{\mathrm{Ce}_{10}\right\}$ cluster 1, view angle emphasizing the domed pentagonal $\left\{\mathrm{Ce}_{5}(\mathrm{Ce})\right\}$ substructure. The $\mathrm{Ce}-\mathrm{O}$ and $\mathrm{Ce}-\mathrm{N}$ bonds of the central fragment shown in purple. (b) The Ce coordination environments in $\mathbf{1}$ with adjoined $\mathrm{Na}^{+}$site (green sphere). Transparent blue triangles highlight the four $\mathrm{Ce}_{3}$ triads surrounding the central $\mathrm{Ce}^{\mathrm{III}} \mathrm{O}_{9}$ group (dark red $\mathrm{Ce}-\mathrm{O}$ bonds). Ce: large blue spheres, $\mathrm{O}$ : red, $\mathrm{N}$ : blue. $\mathrm{C}$ atoms of mda ligands: light grey, carboxylate $\mathrm{C}$ atoms: dark grey.
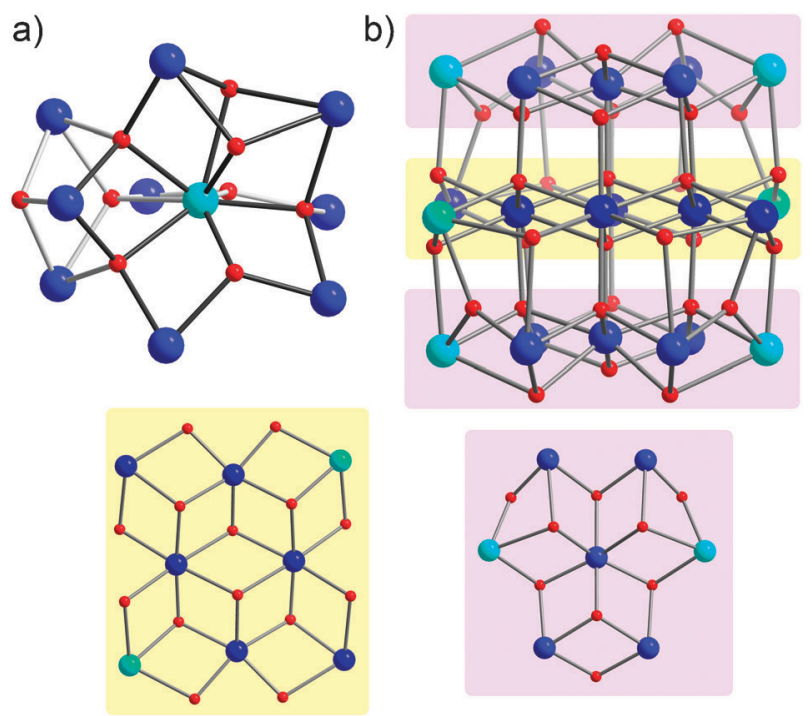

Fig. 2 Central cerium oxide cores in 1 (a) and 2 (b). Only $\mu_{3^{-}}$and $\mu_{4}-\mathrm{O}$ sites are shown for clarity; $\mathrm{Ce}(\mathrm{III})$ : light blue, $\mathrm{Ce}(\mathrm{IV})$ : dark blue, $\mathrm{O}$ : red. Dark grey bonds emphasize the $\left\{\mathrm{Ce}_{5}(\mathrm{Ce})(\mu-\mathrm{O})_{6}\right\}$ pentagon substructure in 1. Bottom: perpendicular views of the $\mathrm{Ce}_{8}$ (left) and $\mathrm{Ce}_{7}$ (right) layers defining the sandwich structure of $\mathbf{2}$. metal oxide cluster core $\left\{\mathrm{Ce}_{22} \mathrm{O}_{24}\right\}$, consisting of three almost planar layers. The outer layers comprise six $\mathrm{Ce}$ ions with a seventh at the center, whereas the central layer consists of eight $\mathrm{Ce}$ centers. The two $\mathrm{Ce}_{7}$ and one $\mathrm{Ce}_{8}$ layers are interlinked by ten $\mu_{3}-\mathrm{O}$ and twelve $\mu_{4}-\mathrm{O}$ sites. Two additional $\mu_{3}-\mathrm{O}$ donors connect three $\mathrm{Ce}$ atoms in the upper and bottom $\mathrm{Ce}_{7}$ layers. The Ce sites in $\mathbf{2}$ are additionally linked to 26 isobutyrate and four tme bridging ligands that define the outer surface of the cluster. BVS calculations confirm a mixed-valent $\mathrm{Ce}^{\mathrm{III}}{ }_{6} \mathrm{Ce}^{\mathrm{IV}}{ }_{16}$ scenario with six of the outermost Ce sites in oxidation state + III (Fig. $2 b$ and Table S2, ESI $\dagger)$. The $\mathrm{CeO}_{n}$ coordination environments $(n=7,8,9)$ show $\mathrm{Ce}^{\mathrm{IV}}-\mathrm{O}$ bond lengths of 2.059-2.705 $\AA$ and $\mathrm{Ce}^{\mathrm{III}}-\mathrm{O}$ bond lengths of 2.301-2.744 $\AA$, consistent with previously reported $\mathrm{Ce}^{\mathrm{III}} \mathrm{O}_{n}$ and $\mathrm{Ce}^{\mathrm{IV}} \mathrm{O}_{n}$ environments. O6 and $\mathrm{O} 13$ and their symmetry equivalents are monoprotonated according to their BVS values (1.369 and 1.349, respectively). Importantly, the two most central $\mathrm{Ce}(\mathrm{IV})$ positions in $\mathbf{2}$ assume a regular cubic $\mathrm{CeO}_{8}$ environment that represents a subsection of the fluorite structure type of the extended crystal lattice of cerium(Iv) oxide (Fig. 3b). This is in stark contrast to the structural chemistry of classical polyoxometalates, which with increasing nuclearity assume increasingly complex, building block-based structures, diverging from the closest-packed structures of their respective solid-state oxides. $^{9}$

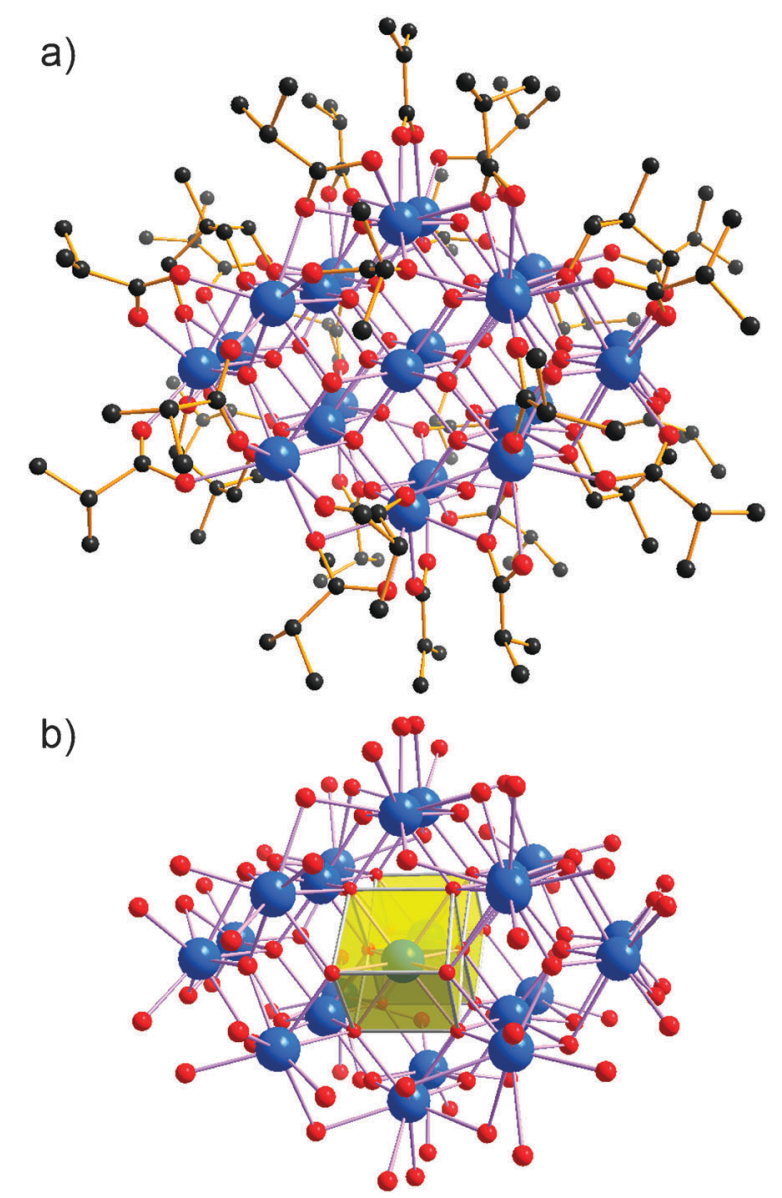

Fig. 3 (a) Structure of $\mathbf{2}$ (color codes as in Fig. 1). (b) The central cerium oxide core. The two edge-sharing $\mathrm{Ce}^{\mathrm{IV}} \mathrm{O}_{8}$ cubes, a subsection of $\mathrm{CeO}_{2}$, are shown as transparent yellow polyhedra. The $\mathrm{Ce}_{7}$ and $\mathrm{Ce}_{8}$ layers (Fig. 2b) run diagonal in the chosen perspective. 
Despite the charge neutrality of the final products $\mathbf{1}$ and $\mathbf{2}$, their $\mathrm{Ce}(\mathrm{III})$ : $\mathrm{Ce}(\mathrm{Iv})$ ratios $(\mathbf{1}: 1: 9, \mathbf{2}: 6: 16)$ reflect that an increasing $4 \mathrm{f}$ electron density results in a higher nucleophilicity of the transient reaction intermediates, in turn driving condensation reactions and molecular growth to larger nuclearities - a fundamental mechanism in polyoxometalate chemistry. Given the relatively long reaction times, the kinetic 'shrink-wrapping' effect frequently observed for the employed ligands ${ }^{10}$ is not likely operational in the formation of $\mathbf{1}$ and $\mathbf{2}$.

In summary, condensation reactions in the presence of minimal water amounts and bulky, structure-directing ligands (carboxylates, polyalkoxides, and aminopolyalkoxides) provide a path to high-nuclearity cerium(III/IV) oxide-based clusters. 1 and $\mathbf{2}$ represent Robin-Day class I mixed-valence compounds, and BVS calculations allow for an unambiguous assignment of (formal) oxidation states. In comparison, mixed-valent polyoxovanadates and -molybdates tend towards class II or III compounds, and a localization of $n$ d electron density usually requires metal-metal bonding interactions, for example in the $\mathrm{Mo}^{\mathrm{V}}(\mathrm{O})(\mu-\mathrm{O})_{x} \mathrm{Mo}^{\mathrm{V}}(\mathrm{O})$ building blocks of Keplerate and $\left\{\mathrm{Mo}_{57} \mathrm{M}_{6}\right\}$-type structures. ${ }^{7}$ Whereas several aspects, from structural similarities between the $\left\{\mathrm{Ce}_{10}\right\}$ system to polyoxometalates and an increase in cluster nuclearity with increasing metal-centered electron density, suggest a conceptual similarity to classical polyoxometalate chemistry, the tendency to approach the thermodynamically stable parental oxide phase is already apparent from the compact layer-type structure of $\left\{\mathrm{Ce}_{22}\right\}$ and its central fluorite-type nucleus. Motivated by preliminary cyclic voltammetry studies pointing to reversible redox processes for $\mathbf{2}$ (in DMF solution) which suggest that the cluster charge and reactivity can be fine-tuned, we will probe these systems' propensity for magnetic functionalization and further molecular growth to even larger cerium oxide clusters. Furthermore, we will also explore the potential of high-nuclearity mixed-valent cerium oxide clusters as precursors for the synthesis of complex oxides, in line with what has been demonstrated with high-nuclearity mixed-valent polyoxometalates. ${ }^{11}$

\section{Notes and references}

$\ddagger$ Synthesis of $\left[\mathrm{Ce}_{2}(\mathrm{ib})_{6}\left(\mathrm{H}_{2} \mathrm{O}\right)_{3}\right]_{n}$ (3). A warm solution of isobutyric acid $(1.26 \mathrm{~mL})$ and $0.54 \mathrm{~g}(13.5 \mathrm{mmol}) \mathrm{NaOH}$ in $20 \mathrm{~mL}$ EtOH and $5 \mathrm{~mL} \mathrm{H}_{2} \mathrm{O}$ was added to a warm solution of $2.0 \mathrm{~g}(4.6 \mathrm{mmol})$ $\mathrm{Ce}\left(\mathrm{NO}_{3}\right)_{3} \cdot 6 \mathrm{H}_{2} \mathrm{O}$ in $20 \mathrm{~mL} \mathrm{H} \mathrm{H}_{2} \mathrm{O}$. The resulting solution was left in a covered flask overnight. The formed colorless crystals were filtered off, washed with water and ethanol and dried in air (yield: $1.25 \mathrm{~g}, 63.4 \%$ based on Ce). Elemental analysis, calcd. (found) for $\mathrm{C}_{24} \mathrm{H}_{48} \mathrm{O}_{15} \mathrm{Ce}_{2}$ : C, 33.64 (34.18); H, 6.02 (5.29)\%. IR (KBr pellet, $\nu / \mathrm{cm}^{-1}$ ): $3423 \mathrm{br} / \mathrm{m}$, $2967 \mathrm{~m}, 2926 \mathrm{sh}, 2871 \mathrm{w}, 1592 \mathrm{vs}, 1472 \mathrm{~m}, 1419 \mathrm{~s}, 1372 \mathrm{w}, 1285 \mathrm{~m}$, $1225 \mathrm{w}, 1095 \mathrm{~m}, 927 \mathrm{~m}, 840 \mathrm{~m}, 802 \mathrm{w}, 607 \mathrm{~m}$.

$\left[\mathrm{NaCe}_{10} \mathrm{O}_{7}(\mathrm{OH})(\mathrm{ib})_{14}\left(\mathrm{HCO}_{2}\right)(\mathrm{mda})_{5}\right]$ (1). To a solution of $0.10 \mathrm{~g}$ $(0.11 \mathrm{mmol})\left[\mathrm{Ce}_{2}(\mathrm{ib})_{6}\left(\mathrm{H}_{2} \mathrm{O}\right)_{3}\right]_{n}(3)$ and $0.01 \mathrm{~g}(0.09 \mathrm{mmol})$ sodium isobutyrate in $5 \mathrm{~mL}$ MeCN were added $0.06 \mathrm{~mL}(0.50 \mathrm{mmol}) \mathrm{H}_{2} \mathrm{mda}$. The resulting solution was heated to $75^{\circ} \mathrm{C}$ in an ultrasonic bath for $1 \mathrm{~h}$ $(80 / 320 \mathrm{~W}, 35 \mathrm{kHz})$, filtered off and left in a covered vial for three days. Dark yellow crystals were separated by filtration, washed with $\mathrm{MeCN}$ and dried in air (yield: $0.031 \mathrm{~g}, 39 \%$ based on Ce). Elemental analysis, calcd. (found) for $\mathrm{C}_{82} \mathrm{H}_{155} \mathrm{~N}_{5} \mathrm{O}_{48} \mathrm{Ce}_{10} \mathrm{Na}$ : C, 28.93 (28.91); H, 4.59 (4.54); N, 2.05 (2.08); Na (ICP-OES), $0.67(0.68) \%$. IR (KBr pellet, $\left.\nu / \mathrm{cm}^{-1}\right)$ : $3432 \mathrm{br} / \mathrm{m}, 2966 \mathrm{~m}, 2927 \mathrm{sh}, 2867 \mathrm{~m}, 1551$ vs, $1478 \mathrm{~s}, 1424 \mathrm{~s}, 1373 \mathrm{~m}$, 1359 sh, 1286 m, 1221 w, 1168 w, 1079 m, 1033 w, 995 w, 924 sh, 897 w, $847 \mathrm{w}, 758 \mathrm{w}, 612 \mathrm{~m}, 562 \mathrm{w}$. UV/Vis (EtOH solution, $\left.\lambda_{\max } / \mathrm{nm}\right): 305$ (br).

$\left[\mathrm{Ce}_{22} \mathrm{O}_{20}(\mathrm{OH})_{4}(\mathrm{ib})_{26}(\mathrm{tme})_{4}\right](2)$. To a solution of $0.10 \mathrm{~g}(0.11 \mathrm{mmol})$ $\left[\mathrm{Ce}_{2}(\mathrm{ib})_{6}\left(\mathrm{H}_{2} \mathrm{O}\right)_{3}\right]_{n}(3)$ in $5 \mathrm{~mL} n \mathrm{PrOH}$ were added $0.06 \mathrm{~g}(0.49 \mathrm{mmol})$ $\mathrm{H}_{3}$ tme. The resulting solution was refluxed for $3 \mathrm{~h}$, filtered off and left in a closed vial for four weeks. Dark yellow crystals were separated by filtration, washed with $n \mathrm{PrOH}$ and dried in air (yield: $0.018 \mathrm{~g}, 28 \%$ based on Ce). Elemental analysis, calcd. (found) for $\mathrm{C}_{124} \mathrm{H}_{222} \mathrm{O}_{88} \mathrm{Ce}_{22}$ : C, 24.01 (24.06); H, 3.61 (3.59)\%. IR (KBr pellet, $\nu / \mathrm{cm}^{-1}$ ): $3566 \mathrm{w}, 3443$ br/m, $2968 \mathrm{~m}, 2931 \mathrm{sh}, 2873 \mathrm{w}, 1627 \mathrm{w}, 1525 \mathrm{~s}, 1475 \mathrm{~s}, 1416 \mathrm{vs}, 1374 \mathrm{~m}$, $1361 \mathrm{sh}, 1287 \mathrm{sh}, 1274 \mathrm{~m}, 1170 \mathrm{w}, 1094 \mathrm{~m}, 926 \mathrm{w}, 849 \mathrm{w}, 723 \mathrm{w}, 579 \mathrm{w}$, $495 \mathrm{~s}, 459 \mathrm{sh}, 436 \mathrm{w}$. UV/Vis (DMF solution, $\lambda_{\max } / \mathrm{nm}$ ): 300 (br).

Single-crystal X-ray diffraction experiments were carried out on Bruker APEX II CCD $(\mathbf{1}, \mathbf{2})$ and Bruker APEX CCD diffractometers (3) using graphite monochromated $\mathrm{MoK} \alpha$ radiation with a detector distance of about $50 \mathrm{~mm}$. Full-sphere data collections with exposures of $40 \mathrm{~s}$ per frame were made with $\omega$ scans in the range $0-180^{\circ}$ at $\varphi=0$, 120 , and $240^{\circ}$. A semi-empirical absorption correction was based on a fit of a spherical harmonic function to the empirical transmission surface as sampled by multiple equivalent measurements ${ }^{12}$ using SADABS software. ${ }^{13}$ All structures were solved using direct methods resulting in chemically reasonable models with an easily distinguished $\mathrm{Ce}_{n} \mathrm{O}_{m}$ core. The remaining atoms were located in alternating series of least-squares cycles on a difference Fourier map. All non-hydrogen atoms were refined in full-matrix anisotropic approximation. All hydrogen atoms were placed in the structure factor calculation at idealized positions and were allowed to ride on the neighboring atoms with relative isotropic displacement coefficients. All calculations were performed using the Bruker APEX II software suite. Structural determination details are summarized in Table S1, ESI. $\dagger$ CCDC $809326,836104,836105$ contain the supplementary crystallographic data for this communication.

1 R. G. Finke and S. Ozkar, Coord. Chem. Rev., 2004, 248, 135; D.-L. Long, R. Tsunashima and L. Cronin, Angew. Chem., Int. Ed., 2010, 49, 1736; A. Proust, R. Thouvenot and P. Gouzerh, Chem. Commun., 2008, 1837; I. A. Weinstock (Ed.), special issue on "Frontiers in Metal Oxide Cluster Science", Isr. J. Chem., 2011, 51, 173-302.

2 P. Kögerler, B. Tsukerblat and A. Müller, Dalton Trans., 2010, 39, 21; J. M. Clemente-Juan and E. Coronado, Coord. Chem. Rev., 1999, 193-195, 361.

3 I. L. Malaestean, M. Speldrich, A. Ellern, S. G. Baca and P. Kögerler, Dalton Trans., 2011, 40, 331; I. L. Malaestean, M. Kutluca, M. Speldrich, A. Ellern and P. Kögerler, Inorg. Chim. Acta, DOI: 10.1016/j.ica.2011.08.061.

4 R. Das, R. Sarma and J. B. Baruah, Inorg. Chem. Commun., 2010, 13, 793; P. Toledano, F. Ribot and C. Sanchez, C. R. Acad. Sci., Ser. II, 1990, 311, 1315; V. Mereacre, A. M. Ako, M. N. Akhtar, A. Lindemann, C. E. Anson and A. K. Powell, Helv. Chim. Acta, 2009, 92, 2507.

5 See e.g. X.-J. Kong, Y. Wu, L.-S. Long, L.-S. Zheng and Z. Zheng, J. Am. Chem. Soc., 2009, 131, 6918; J.-W. Cheng, J. Zhang, S.-T. Zheng, M.-B. Zhang and G.-Y. Yang, Angew. Chem., Int. Ed., 2006, 45, 73; X. Gu and D. Xue, Inorg. Chem., 2007, 46, 3212 and references therein; L. Huang, L. Han, W. Feng, L. Zheng, Z. Zhang, Y. Xu, Q. Chen, D. Zhu and S. Niu, Cryst. Growth Des., 2010, 10, 2548 and references therein.

6 M. T. Pope and A. Müller, Angew. Chem., Int. Ed. Engl., 1991, 30, 34; M. T. Pope, Heteropoly and Isopoly Oxometalates, Springer, Berlin, 1983.

7 A. Müller, P. Kögerler and C. Kuhlmann, Chem. Commun., 1999, 1347; A. Müller, P. Kögerler and H. Bögge, Struct. Bonding, 2000, 96, 203.

8 P. L. Roulhac and G. J. Palenik, Inorg. Chem., 2003, 42, 118.

9 See e.g. A. Müller, E. Beckmann, H. Bögge, M. Schmidtmann and A. Dress, Angew. Chem., Int. Ed., 2002, 41, 1162; X. Fang, P. Kögerler, Y. Furukawa, M. Speldrich and M. Luban, Angew. Chem., Int. Ed., 2011, 50, 5212.

10 I. L. Malaestean, V. C. Kravtsov, M. Speldrich, G. Dulcevscaia, Y. A. Simonov, J. Lipkowski, A. Ellern, S. G. Baca and P. Kögerler, Inorg. Chem., 2010, 49, 7764; I. L. Malaestean, M. Speldrich, A. Ellern, S. G. Baca, M. Ward and P. Kögerler, Eur. J. Inorg. Chem., 2009, 4209.

11 M. Sadakane, K. Yamagata, K. Kodato, K. Endo, K. Toriumi, Y. Ozawa, T. Ozeki, T. Nagai, Y. Matsui, N. Sakaguchi, W. D. Pyrz, D. J. Buttrey and W. Ueda, Angew. Chem., Int. Ed., 2009, 48, 3782.

12 R. H. Blessing, Acta Crystallogr., Sect. A, 1995, 51, 33.

13 G. M. Sheldrick, Acta Crystallogr., Sect. A, 2008, 64, 112. 